\title{
Sentence Translation Challenges among Arabic-Speaking EFL Students
}

\author{
Lana Hussain Ahmed Shahata \\ Department of English, CFY, Majmaah University, Al Majma'ah, KSA \\ Email: Lana.shehata@gmail.com
}

How to cite this paper: Shahata, L. H. A. (2020). Sentence Translation Challenges among Arabic-Speaking EFL Students. Open Journal of Modern Linguistics, 10, 321-339. https://doi.org/10.4236/ojml.2020.104019

Received: July 18, 2020

Accepted: August 21, 2020

Published: August 24, 2020

Copyright $\odot 2020$ by author(s) and Scientific Research Publishing Inc. This work is licensed under the Creative Commons Attribution International License (CC BY 4.0).

http://creativecommons.org/licenses/by/4.0/

\begin{abstract}
The study aims to investigate sentence translation challenges among Arabic-Speaking EFL Students. The study follows both descriptive and analytical methods. The study was applied to students at Omdurman Islamic University college of Education forth year students. The sample of students consists of 30 students who study English at Education College. The study used a test as a tool for data collection and data were analyzed, by SPSS program. The findings of this study emphasized those EFL students facing problems in translation. Students have very weak background knowledge about how to translate English to Arabic; then they do not have sufficient ability to translate Arabic sentences to English, and they are very weak in translating English proverbs into Arabic; students are not acquiring English culture, which affects negatively their abilities of translating English proverbs into Arabic. Based on these findings, the researcher recommended that the translation should be paid attention when it is taught; the translation should be taught from the first year; students should be given many topics to translate during their academic year; students should be taught English proverbs as much as possible during their academic year; the teachers should use motivating methods to enhance the students' level in translation.
\end{abstract}

\section{Keywords}

Translation, Proverbs, Oral, Writing, Literal, Metaphorical, Précis, Interpretative-Computer, Machine, Problem, Free-Characteristics

\section{Introduction}

The researcher reviews the definition of translation by famous figures in field and the previous studies. Translation is a human activity that enables us to communicate. It plays an integral role in bridging the gaps between nations and 
transferring knowledge. Consequently, there is a growing interest in programmes and courses in a number of universities in the Middle East. Different languages give a different way to look at the world but translation provides us opportunity to explore and interact with these different views of world. Translation refers to carrying the meaning of text from one language to another. Most linguistic theories involve several level of analysis of text. One popular conception of the task of translation is the transfer of structure in target language (Catford, 1965: p. 335). Linguistic is the scientific study of language. There are three aspects language form, language meaning, and language in context. Most translation scholars and linguistics agree that the translation process is achieved as communicative process from foreign language to the mother tongue, so translation considers unique linguistic device that has the very important task of conveying the sense of the text from one language to another language. Nida, (1954: p. 322) has, in his discourse on scientific translation pointed to this challenge. He said: if the translation of scientific text from one language to another participating in modern culture development is not too difficult, it is not surprising that that converse is true that translating scientific material from modern Indo-European language into language largely outside the reach of western science is extremely difficult. The English students of university don't know well translation; they lack of the ability of translation of English sentences from English to Arabic and vice versa and they commit errors when they face examinations questions. The students learning English often make mistakes and commit errors while learning English, especially when they try to translate English sentences into Arabic and vice versa. As a result, they write incorrect sentences. The significance of the study is well known that English is considered as a global language. It plays an important role in our life. The importance of this study is that it investigates one of the most significant parts of translation. Students at university level are unable to master this very important part of language. The purpose of this study is to find out whether the learners have or have not ability to translate sentences from English to Arabic and vice versa. The area of the problems confronting Arab university students of English as a foreign language (EFL) when translating Arabic into English and vice versa is extensively studied. Despite the previous studies conducted at Omdurman Islamic University dealing with English language difficulties, research in translation difficulties has not been given sufficient attention. Most of the previous studies focused on difficulties within language skills. There is a lack of empirical studies in translation that could bridge the gap existing in the field of examining the ability of students' translation, and to investigate the committed errors. Consequently, the researcher found it is an indispensable requisite to investigate problems encountered by students, mainly from Arabic into English. In this regard, the present study may shed light on students' ability in translation, in addition to analyzing the committed errors in English into Arabic and vise versa.

Many researchers dealt a scientific translation linguistic that under graduate 
students face problems in translating Arabic scientific text into English. But already been suggested by many translation scholars such as Baker (1992) and Newmark (1988a: p. 215) Newmark (1988b: pp. 80-91) that the notion of equivalences is problematic in the study of translation, and to overcome this problem, various translation strategies have been suggested by various authors within the field of translation. Nida (1964: p. 223) highlights this aspect of scientific translation as follows:

This level of language, experientially is lifeless, is linguistically very manipulatable. For to the extent that language can be separated from the unique qualities of experience and can be made a kind of linguistic mathematics, its units can easily be arranged and re-arranged with little interference from the cultural context. Nida (1964: p. 233) highlights this aspect of scientific translation as follows: It emerges from the above-mentioned comparison between English and Arabic, which drastically lack scientific and technical terminology, suffers an irreversible process of disintegration through diglossia, and harbors scanty abbreviations, acronyms, formulae and registers. But since science and technology create situational features which involve new concepts, techniques, and processes that can be imitated and imagined, it is binding for Arabic translators to coin equivalent terminology and develop corresponding programs of expression which Arabic morphology and flexible word order can provide. However, theoretical possibilities may in many cases fall short of practical application and this is very much the case with English technical translating into Modern Standard Arabic today. However, a part from the cultural gap, the problem of scientific translation from English into Arabic remains mostly a matter of understanding and representing techniques, the processes, and the details which science and technology involve. In this regard, Farghal and Shunnaq (1999: p. 210) state that "the major problem facing translators at scientific text standardization and dissemination in the sphere of science and technology". "When it comes to Arabic", the continue scientific discourse is a translation activity, as Arabic is usually target language, and creation reasoning are done in language.

In comparison with the studies carried out of problems that face students in translation from one language to another. Some of the scholars say the major problems of translation in deferent setting and contexts, but the other says. The problems of translation are problematic in the study of translation, and say remains mostly matter of understanding and presenting the techniques, the processes, and details which science and technology involve. Consequently, the researcher designed a test of translating English sentences into Arabic and vice versa as well as to translate English proverbs into Arabic to show the problems that encountered students when they translate. It is hypothesized that:

1) University students are not able to correctly translate English sentences into Arabic and vice versa.

2) University students are not aware of translating English proverbs into Arabic. 
This study aims:

1) To investigate the problems which face university students in translating English into Arabic and vice virsa correctly.

2) To identify which difficulties faces students when they try to translate English proverbs into Arabic.

According to the aims the research questions are:

1) What is the ability of English students in translation English into Arabic and vice versa at Omdurman Islamic University in Sudan?

2) To what extent do university students able to translate English proverbs into Arabic?

\section{Theoretical Frame Work}

Translation is the transmitted of written text from language into another. Although the terms translation and interpretation one often used inter changeably, by strict definition, translation refer to the written language. Translation is the communication of the meaning of the source, language text by means of an equivalent target, language text. Also translation is procedure which leads from written source language text to an optimally equivalent target language text and requires syntactic, semantic and stylistic and text pragmatic comprehension by translation of the original text. Newmark is rank as another prominent scholar translation studies. According to Newmark (1991), translation is rendering the meaning of text into another language in the way that the author intended to the text. Translation is a phenomenon that has a huge effect on everyday life. This can range from the translation of a key international treaty of the following multilingual poster that welcomes customers to a small restaurant. What is translation? Often, though not by any means always, it is rendering the meaning of a text into another language in the way that the author intended the text. Common sense tells us that this ought to be simple as on ought to be able to say something as well in one language as in another. The scholars have divided translation into many types, as following: oral translation Andrew Tailor (2005), "this translation is done by word of mouth. It is often refereed as interpretations irrespective of the nature of the environment in which it takes place. It may be professional or nonprofessional", written by translation Andrew Tailor (2005). "Here the translation is done in Writing. The text is written from the source language into the target language and is presented in document form”. Computer/machine based translation Andrew Tailor (2005). "This is where the translation of a document is done on word-for-word translation basis. Here, sometimes the meaning of the whole document may not be given much attention but just translate each word the way it is from the original language to the target language". Literal Translation is probably the oldest type of translation practice? It involves conveyance of denotative meaning of phrases and sentence in text from one language to another. Metaphorical Translation: Involves the translation of SL, metaphor into TL, metaphors. It is inevitable in literary translation; 
serious work of literature abounds in creative metaphors. Precis Translation Is translation method where by the translator gives TL summary of the SL text he is dealing with. Such TL summary translation usually provide the reader with only the main point of the SL text, thus ignoring many find detail that deemed contextually unimportant or, even irrelevant. Free Translation and Adaptation Translation method whereby an SL, literary text is relayed into the TL, by reproducing the matter without the manner, or the content without the form. There for, it is usually paraphrase that is much longer than the original and often wordy and pretentious as for adaptation, it another translation method whereby the SL text is freely translated into TL. Interpretive translations Andrew Tailor (2005), "there are translations provide further interpretation, descriptions and meaning of the original or source text but not just simply the translation of words in the text of document". Because literature consists of conventional symbols, there exists in literature the problem of translation which does not exist in the other arts. When one seeks to make a work of literature available to a wider audience than that composed of only the native speakers of the language in which the work was written, the process of translation must be restored to and in the process a great deal of the work's original character is lost. In a poem there are 1) sounds 2) the dictionary meanings of the words 3 ) the connotations of the words-The manifold associations that they evoke (sensory, intellectual and emotional) in the minds of the readers. The sounds are the least important of the three, and many a great poem as sheer sound is hardly ever pleasing. The finding of like dictionary meanings is usually a simple matter and when there is a word that has no rough equivalent in the other language, it may be simply retained in the original language (for example, the Sanskrit word Dhanna or yoga is retained in English translation of Sanskrit works). As for the associations that hover about a word, they may vary from one language to another, so that if a work translated rather literally, the associative values of the words are lost. Thus Karnbin Kaanada, if-translated into English, literally, may mean "cut the wire" though it is Encyclopedia Britanica Vol., 25 PP 698 literally comb it is an unfaith translation because it actually means "take to heels". Words can often be found in the second language that have a roughly equivalent associative value to the original, but these will usually not provide a literal translation; thus the translator is faced with the dilemma of being able to provide the literal meaning translation or a translation that renders the spirit or "feel" of the original, but not both. The task of the translator is the same whether the material is oral or written, but of course, translation between written texts allows more time for stylistic adjustments and technical expertise. The main problems have been recognized since antiquity and were expressed by St. Jomes, translator of the famed Latin Bible, the Vulgate, form the Hebrew and Greek originals. Semantically, these problems relate to the adjustment of the literal and the literary translation of each word, as far as his is possible, and the production of a whole sentence or even a whole text that conveys as much of the meaning of the original as can be 
managed, these problems and conflicts arise because of factors already noticed in the use and functioning of language; languages do not operate in isolation but within and as a part of cultures. And cultures differ from each other in various ways, even between the languages of communities whose cultures are fairly closely allied, there is by no means a one-to-one relation of exact lexical equivalence between the items of their vocabularies. In their lexical meanings, words acquire various overtones and associations that are not shared by the nearest corresponding words in other languages; this may vitiate a literal translation. The basic and fundamental problem of translation lies in the level of comprehension of some language text as an ordinary reader does, and then the expression of it in the target language, a student of literature or translation in the process of learning may be pardoned for his faulty comprehension or poor ability to express it in the target language. But a poet translator of notable stature, whose translation gets published, has no excuse. He cannot afford to make mistakes, at least at the comprehension level. "Difficulties and Problems arising from translation process fell into four categories: 1) Cultural difficulties: Include the proper or improper usage of certain word, phrases based on the culture of a given society as well as the specifies of the society itself such as the education system, health care system, societal or religious taboos ... etc. 2) Conceptual/Semantic difficulties: Are those that arise in conveying the meaning of statement in a foreign language. 3) Idiomatic difficulties: Correspond to use of certain phrases, or the means of conveying ideas that are unique to a particular region, country or society. 4) Grammatical difficulties: Include difficulties linked for and based on for instance to the grammar of a given language" (Nakhallah, 2016). Translation problems also demands solutions to process the problems which are in translation. According to (Ghazala, 2008), the solutions proposed to translation problems are, therefore, based on the following criteria: 1) The types of text: general, technical, religious, political, etc. 2) The minor linguistic context: the preceding and the following word, phrase, clause or sentence. 3) The possibility of saying something in the Target Language or not (e.g. for "fat salary" we can say (ضخمر اتب), but not (سمينر اتب). 4) The possibility or not of using an identical Target Language grammatical structure. 5) The understandability or not of an expression (e.g. "tall order" is understood when translated into (شة|قةمهمةة), (but not understood as (طويل).أمةر). According to Russo (1983) "the definition of a proverb has caused scholars from many disciplines much chagrin over the centuries. Many attempts at definition have been made from Aristotle to the present time, ranging from philosophical considerations to cut-and-dry lexicographical definitions" (in Meider, 2004). Meider \& Dundes (1985) has defined the proverb as "a short, generally known sentence of the folk which contains wisdom, truth, morals, and traditional views in a metaphorical, fixed and memorable form and which is handed down from generation to generation". $\mathrm{He}$ also points to some proverbs which refer to the definition of proverbs for example; "Proverbs are the children of experience", "Proverbs are the wisdom of the 
streets", and "Proverbs are true words". "Proverbs obviously contain a lot of common sense, experience, wisdom, and truth, and as such they represent ready-made traditional strategies in oral speech acts and writings from high literature to the mass media". Mollanazar (2001: p. 53) has defined the proverb as "a unit of meaning in a specific context through which the speaker and hearer arrives at the same meaning". And the last but not the least Norrick (1985a: p. 78) has proposed the following definition for the proverb: "The proverb is a traditional, conversational, didactic genre with general meaning, a potential free conversational turn, preferably with figurative meaning".

Characteristics of proverbs Different characteristics have been proposed for proverbs by various scholars in the field of parasitology. Here the ideas of two influential scholars will be referenced. Norrick (1985b: pp. 32-34) gathering the disperse features proposed by various scholars, has proposed the following characteristics which help us to identify the proverbs from other similar items. These characteristics are as follow: Proverbs are self-contained: Seiler has argued that proverbs must be self-contained by which he means that none of their essential grammatical units may be replaced. In Norrick's words Seiler introduces this definitional criterion solely to distinguish proverbs from proverbial phrases. With reference to these characteristics in Norrick's words "proverbial phrases like 'to face the music' and 'Brown as a berry' are immediately excluded from the class of proverbs because they lack precisely essential grammatical units, which can thus be substituted into them at will". Proverbs are (propositional) statement: Abrahams is perhaps more precise in requiring the proverb to be a full statement. Proverbs are (grammatical) sentences: Taylor determines that proverbs must be complete (if elliptical) sentences. Besides, writers such as Abrahams, Holneck, and Meider, also accept complete sentence status as a property of the proverbs. Journal of Language Teaching and Research () 2010 Academy Publisher 808. Proverbs are tradition: The traditional nature of proverbs correlates closely with their status as items of folkloric. According to Norman C (1995: p. 62) in English the order of words in a statement is subject:

1) Verb + object:

$\begin{array}{ll}\text { Subject } & + \text { verb } \\ \text { I } & \text { enjoy } \\ \text { Peter } & \text { is watching } \\ \text { She } & \text { drank }\end{array}$

- Some verbs e.g. go do not have an object:

Steven has gone

The train didn't arrive

Anna and Tom are swimming.

- Some verbs e.g. like always need an object:

I like music

She wants a drink

- After the verbs (be), we can use an object or an adjective. 
She is a doctor object

Mary is tired adjective

After some verbs e.g. (give, send, bring) we can talk about a person (Mary, her) and object.

$\begin{array}{lll}\text { Verb } & + \text { person } & + \text { object } \\ \text { He sends } & \text { Jane } & \text { a book } \\ \text { Anna made } & \text { Tom } & \text { a cup of tea } \\ \text { She wrote } & \text { him } & \text { a letter }\end{array}$

- We usually put information about times or places at the end of the sentences:

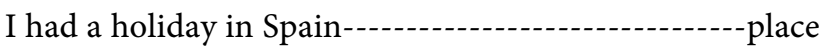

They have their son a watch yesterday----------------time

All sentences are made up of words and each word in a sentence function as a specific part of speech.

Noun: a noun is the name of a person, place or thing; it names nouns anything that may be the topic of discussion.

Pronoun: a pronoun is a word that takes the place of noun. It replaces a noun without naming it.

Preposition: is the word that is used with noun or pronouns to forms a phrase that shows location, owner ship, identification, time, or exclusion within the sentences...

Verbs: is a word that shows action, existence, or a state of being it may be one word or a verb phrase with two or more words.

Adjective: is a word that describes of modifies a noun or pronoun. It is answer which one, what kind, or how many (The articles a, an, and they are adjectives).

Adverb: is a word that describes or modifies verb, an adjective or another adverb. It answers when, where, how much. It may be found in different places in sentence if it modifies verb but not if it modifies an adjective or other verb very and not are always adverbs.

Conjunction: is a word that joins one part in sentences to another part, it may be join words, phrases, clauses or sentences. Interjection: is an exclamatory word that show story feeling. This research is expected to give a significant background about the problems that face Sudanese Students in translation particularly at Omdurman Islamic University. This study is attempt to survey and classify the problem that face students in translation at Omdurman Islamic University It will benefit postgraduate students and scholars in carrying out similar research and studies.

\section{Method}

The research uses a descriptive analytical method. The researcher uses a test asking students to translate English sentences in to Arabic and vice versa as well as to translate English proverbs into Arabic, and then the researcher will analyze the problems of sentence translation in terms of grammar aspect and cohesion. EFL students at Omdurman Islamic university represent the population of the 
study. In this study, only one tool is used for data collection. A designed test contains of 15 questions to explore the problems of translating English sentences into Arabic and vice versa as well as translating English proverbs into Arabic of EFL students at Omdurman Islamic University. The researcher used a test to asked students to translate English sentences from Arabic to English and vice versa as well as to translate English proverbs. A test was given EFL students of 4th year in Omdurman Islamic University. The test consists of three parts with fifteen statements. The student's answered are analyzed to explore the problems of translating English sentences into Arabic and vice versa as well as translating English proverbs to Arabic of University students. The researcher distributed the test papers to 30 students selected them randomly to choose exact sample of the study. The subjects for this study were thirty students of English Language Department at Omdurman Islamic University in the Sudanese academic year 2019/2020. Of the 30 participants, 10 were male and 20 were female. When the study was conducted, the subjects had already studied several specialized courses including introduction, translation principles, in addition to literature and skills courses. All the subjects are native speakers of Arabic and they graduated from public or private schools, which means that they had received eight to ten years of instruction in English before joining the university.

\section{Data Analysis, Result and Discussion}

The following tables and figures display the results of data analysis obtained by the means of test.

Table 1 and Figure 1 show that the answer of most of the individuals are (False) by frequency (27) with percent (90\%) while the answer is (True) by frequency (3) with percent (10\%) respectively are very low.

Table 2 and Figure 2 show that the answer of most of the individuals' study is (False) by frequency (23) with percent $(76.7 \%)$ while the answer is (True) by frequency (7) with percent (23.3\%) respectively are low.

Table 3 and Figure 3 show that the answer of most of the individuals study is (False) by frequency (29) with percent $(96.7 \%)$ while the answer is (True) by frequency (1) with percent (3.3\%) respectively are high, so the highest percentage is going to positive direction of the statements and most answers of the study sample are agree able. Therefore, this hypothesis is successfully achieved.

Table 4 and Figure 4 show that the answer of all individuals study is (False) by frequency (30) with percent (100\%) respectively are high, so the highest percentage is going to positive direction of the statements and most answers of the study sample are agreeable. Therefore, this hypothesis is successfully achieved.

Table 5 and Figure 5 show that the answer of all individuals study is (False) by frequency (30) with percent (100\%) respectively are high, so the highest percentage is going to positive direction of the statements and most answers of the study sample are agreeable. Therefore, this hypothesis is successfully 
achieved.

Table 6 and Figure 6 show that the answer of all individuals study is (False) by frequency (30) with percent $(100 \%)$ respectively are high, so the highest percentage is going to positive direction of the statements and most answers of the study sample are agreeable. Therefore, this hypothesis is successfully achieved.

Table 7 and Figure 7 show that the answer of all individuals study is (False) by frequency (30) with percent (100\%) respectively are high, so the highest percentage is going to positive direction of the statement and most answers of the study sample are agreeable. Therefore, this hypothesis is successfully achieved.

Table 8 and Figure 8 show that the answer of most of the individuals study is (True) by frequency (18) with percent (60\%) while the answer is (False) by frequency (12) with percent $(40 \%)$ respectively are low.

Table 9 and Figure 9 show that the answer of most of the individuals study is (False) by frequency (28) with percent (93.3\%)while the answer is (True) by frequency (2) with percent (6.7\%) respectively are high, so the highest percentage is going to positive direction of the statements and most answers of the study sample are agreeable. Therefore, this hypothesis is successfully achieved.

Table 10 and Figure 10 show that the answers of most of the individual's study is (False) by frequency (19) with percent (63.3\%) while the answer is (True) by frequency (11) with percent (36.7\%) respectively are high, so the highest percentage is going to positive direction of the statements and most answers of the study sample are agreeable. Therefore, this hypothesis is successfully achieved.

Table 11 and Figure 11 show that the answer of most of the individuals' study is (False) by frequency (24) with percent (80\%) while the answer is (True) by frequency (6) with percent (20\%) respectively are high, so the highest percentage is going to positive direction of the statements and most answers of the study sample are agreeable. Therefore, this hypothesis is successfully achieved.

Table 12 and Figure 12 show that the answer of all individuals study is (False) by frequency (30) with percent (100\%) respectively are high, so the highest percentage is going to positive direction of the statements and most answers of the study sample are agreeable. Therefore, this hypothesis is successfully achieved.

Table 13 and Figure 13 show that the answers of all individuals study is (False) by frequency (30) with percent (100\%) respectively are high, so the highest percentage is going to positive direction of the statements and most answers of the study sample are agreeable. Therefore, this hypothesis is successfully achieved.

Table 14 and Figure 14 show that the answer of all individuals study is (False) by frequency (30) with percent (100\%) respectively are high, so the highest percentage is going to positive direction of the statements and most answers of the study sample are agreeable. Therefore, this hypothesis is successfully achieved.

Table 15 and Figure 15 show that the answer of all individual's study is (False) by frequency (30) with percent (100\%) respectively are high, so the highest percentage is going to positive direction of the statements and most answers of the study sample are agreeable. Therefore, this hypothesis is successfully achieved. 
Table 1. The frequency distribution's analysis for item one.

\begin{tabular}{ccc}
\hline Answer & Frequency & Percent \\
\hline True & 3 & $10 \%$ \\
False & 27 & $90 \%$ \\
Total & 30 & $100 \%$ \\
\hline
\end{tabular}

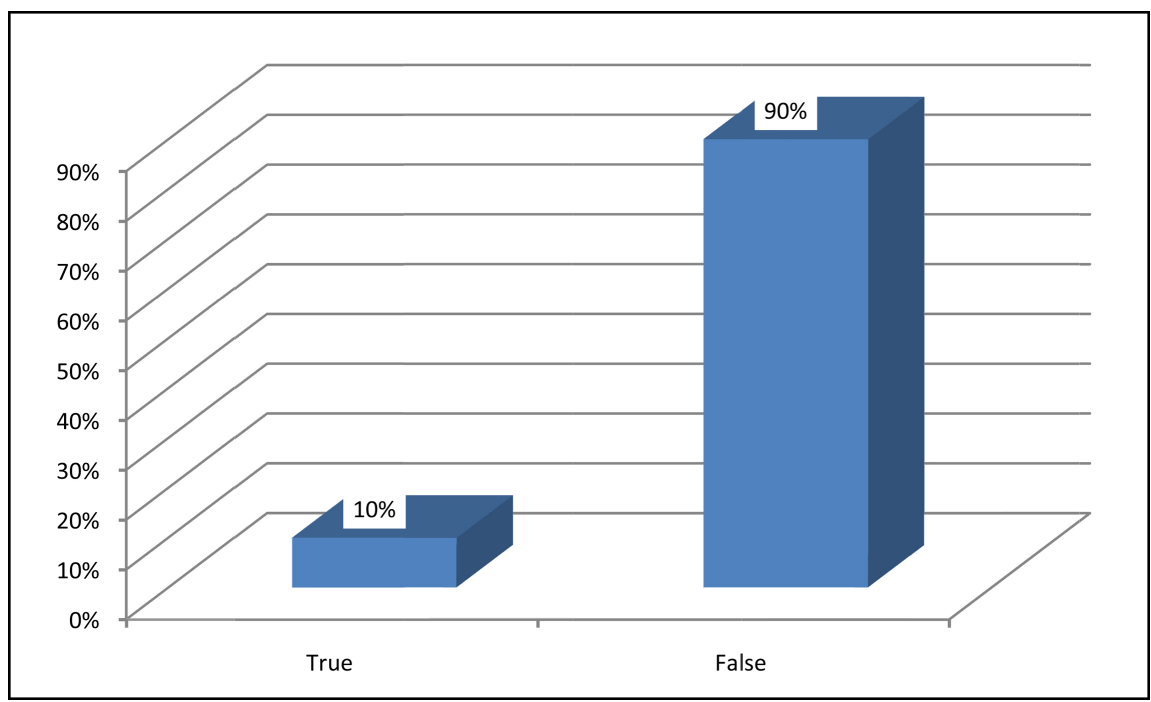

Figure 1. The frequency distribution's analysis for item one.

Table 2. The frequency distribution's analysis for item two.

\begin{tabular}{ccc}
\hline Answer & Frequency & Percent \\
\hline True & 7 & $23.3 \%$ \\
False & 23 & $76.7 \%$ \\
Total & 30 & $100 \%$ \\
\hline
\end{tabular}

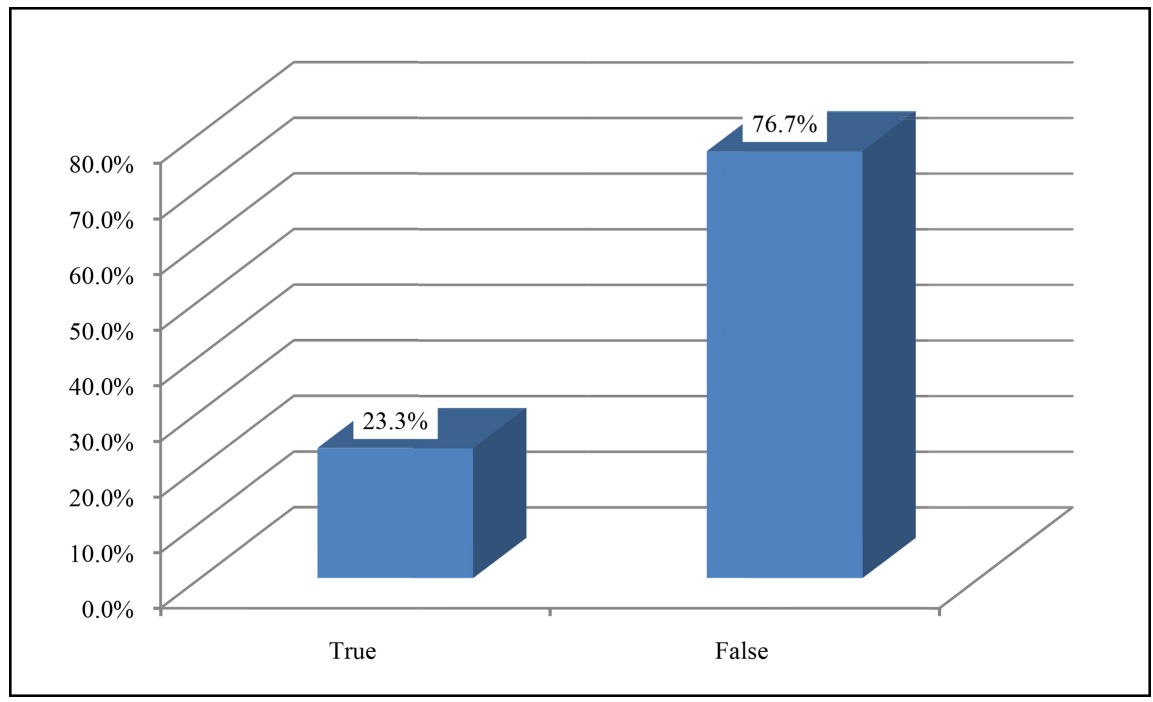

Figure 2. The frequency distribution's analysis for item two. 
Table 3. The frequency distribution's analysis for item three.

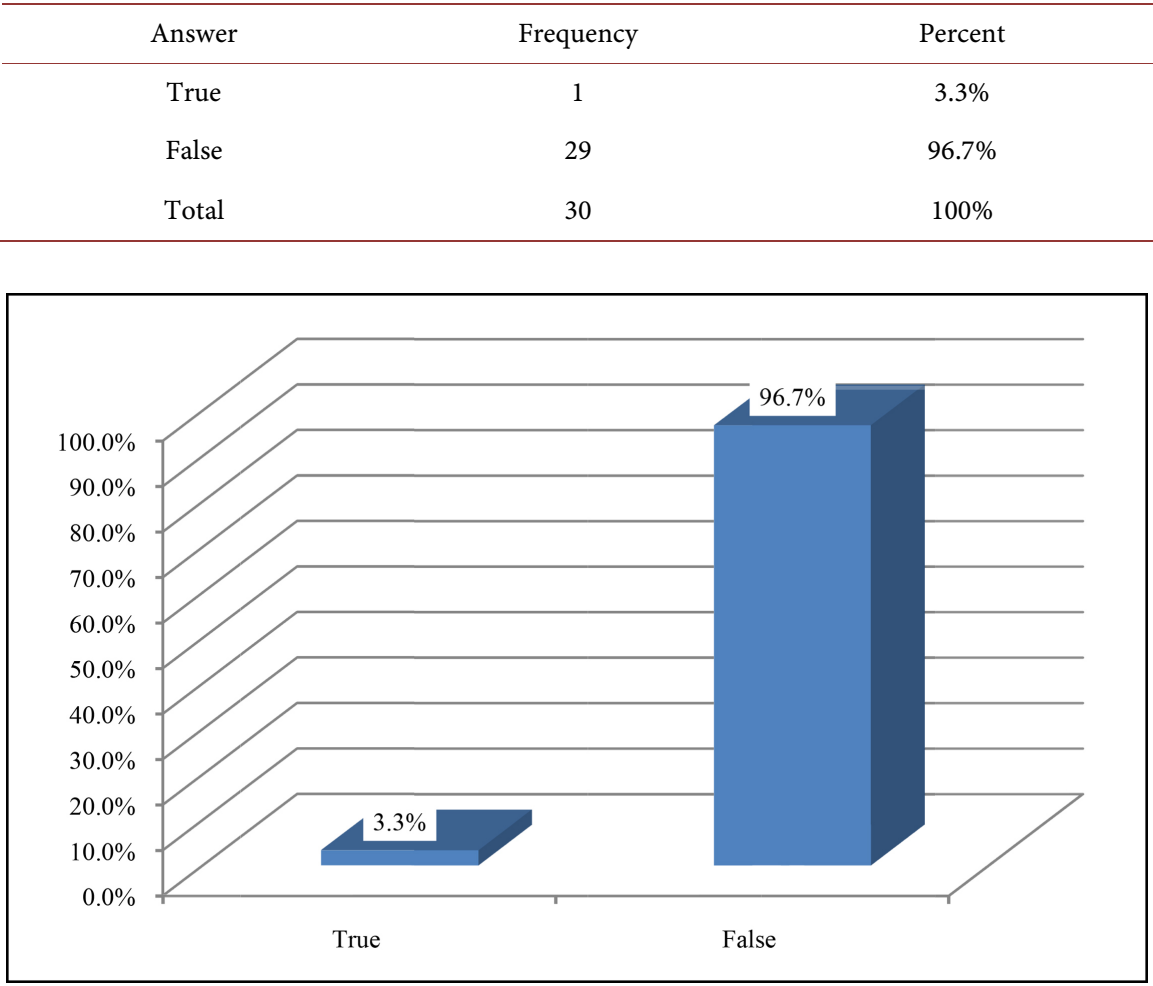

Figure 3. The frequency distribution's analysis for item three.

Table 4. The frequency distribution's analysis for item four.

\begin{tabular}{ccc}
\hline Answer & Frequency & Percent \\
\hline True & 0 & $0.0 \%$ \\
False & 30 & $100 \%$ \\
Total & 30 & $100 \%$ \\
\hline
\end{tabular}

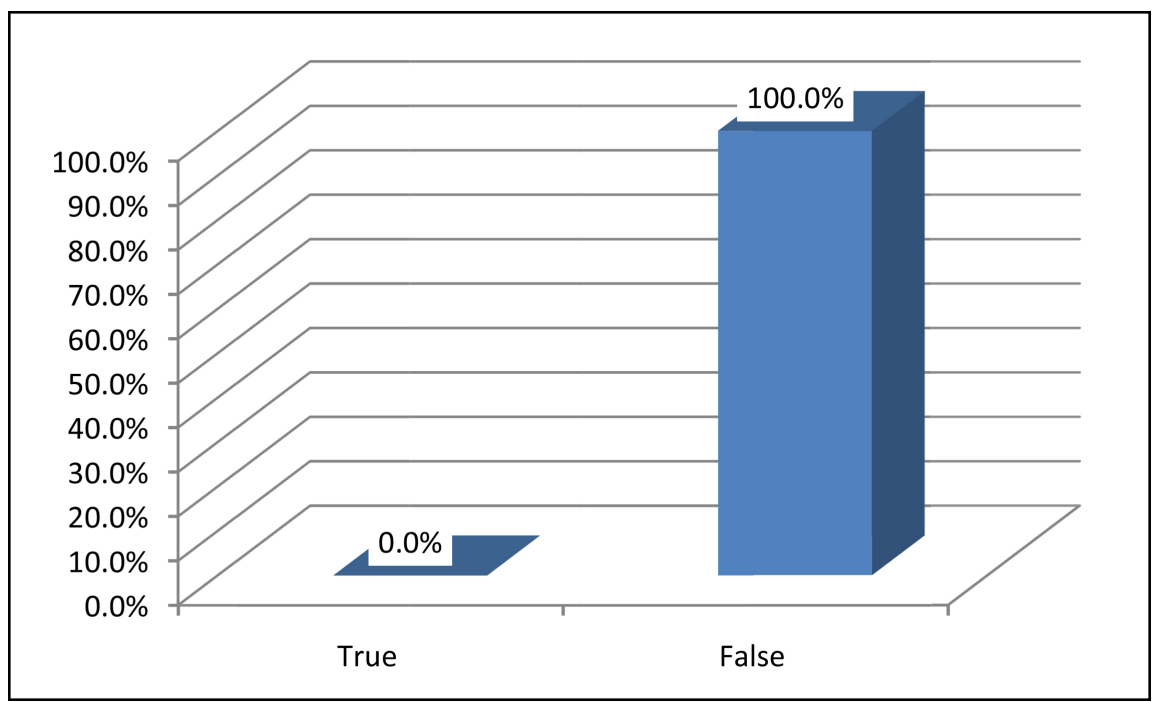

Figure 4. The frequency distribution's analysis for item four. 
Table 5. The frequency distribution's analysis for item five.

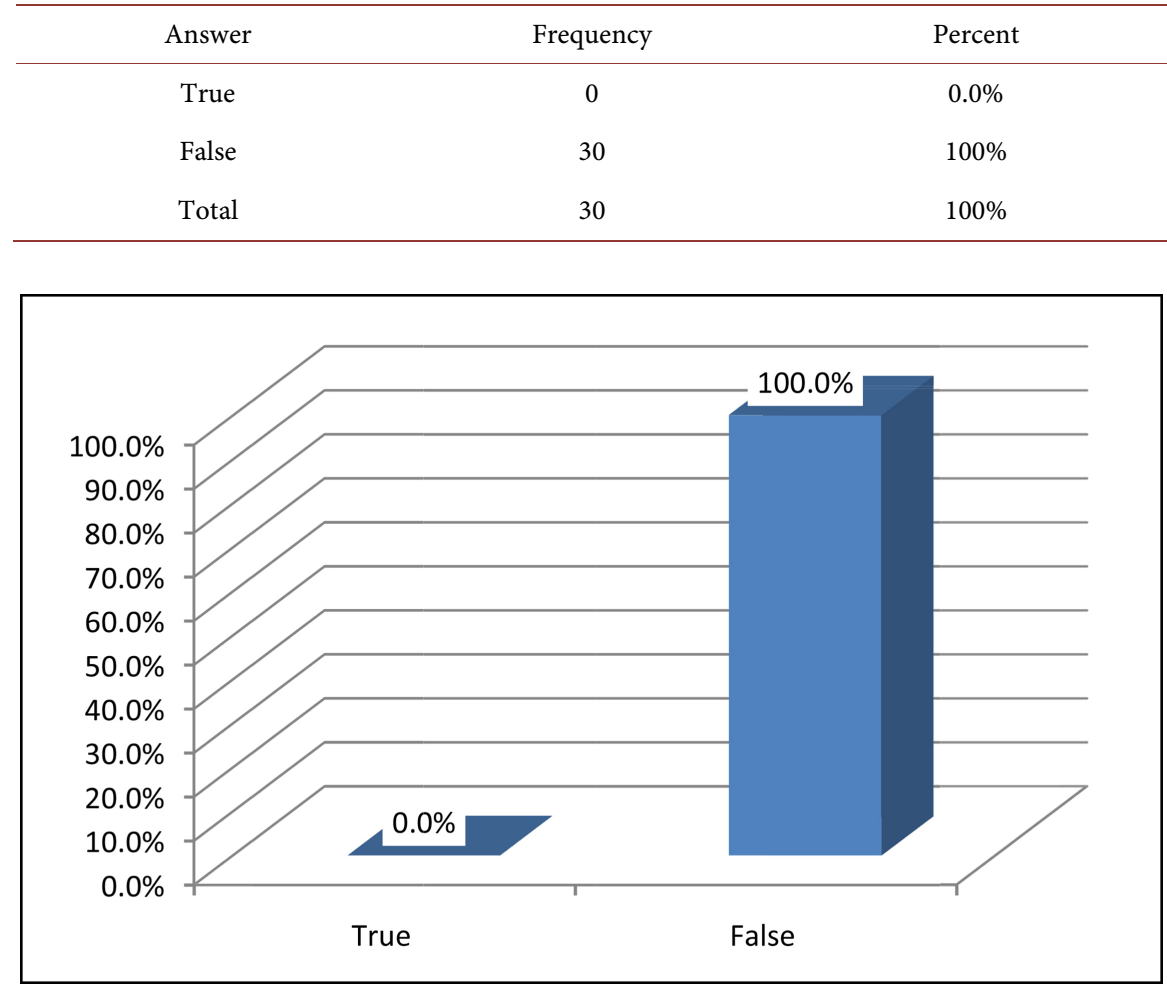

Figure 5. The frequency distribution's analysis for item five.

Table 6. The frequency distribution's analysis for item six.

\begin{tabular}{ccc}
\hline Answer & Frequency & Percent \\
\hline True & 0 & $0.0 \%$ \\
False & 30 & $100 \%$ \\
Total & 30 & $100 \%$ \\
\hline
\end{tabular}

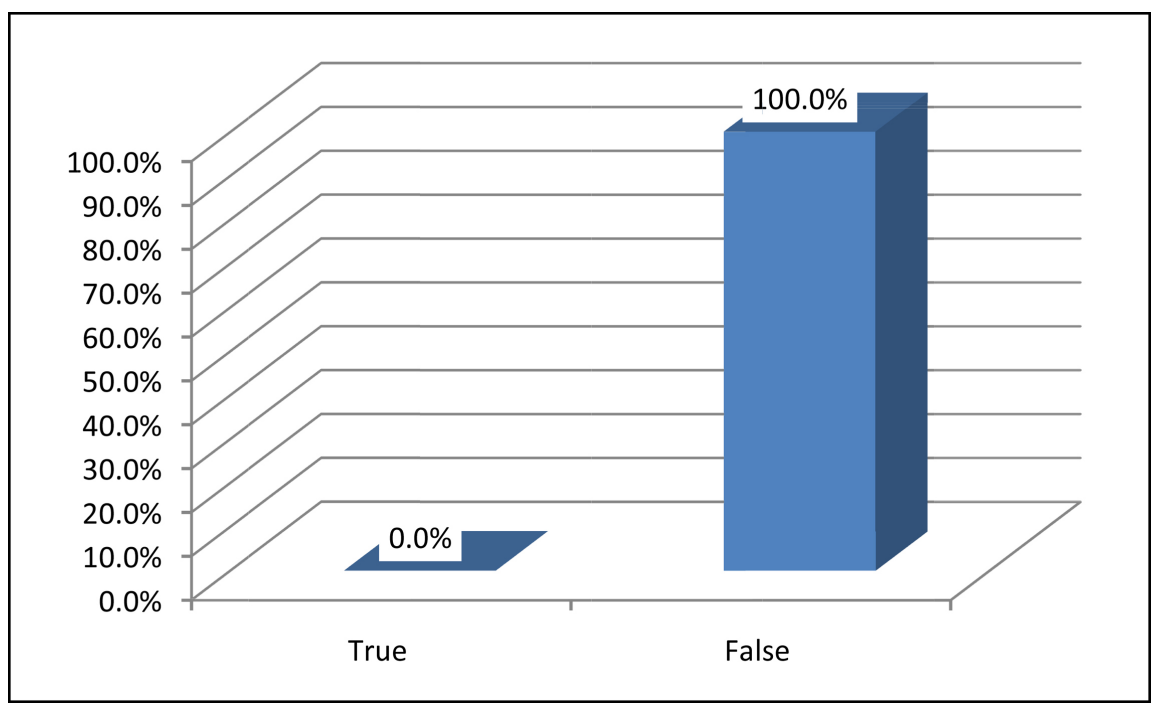

Figure 6. The frequency distribution's analysis for item six. 
Table 7. The frequency distribution's analysis for item seven.

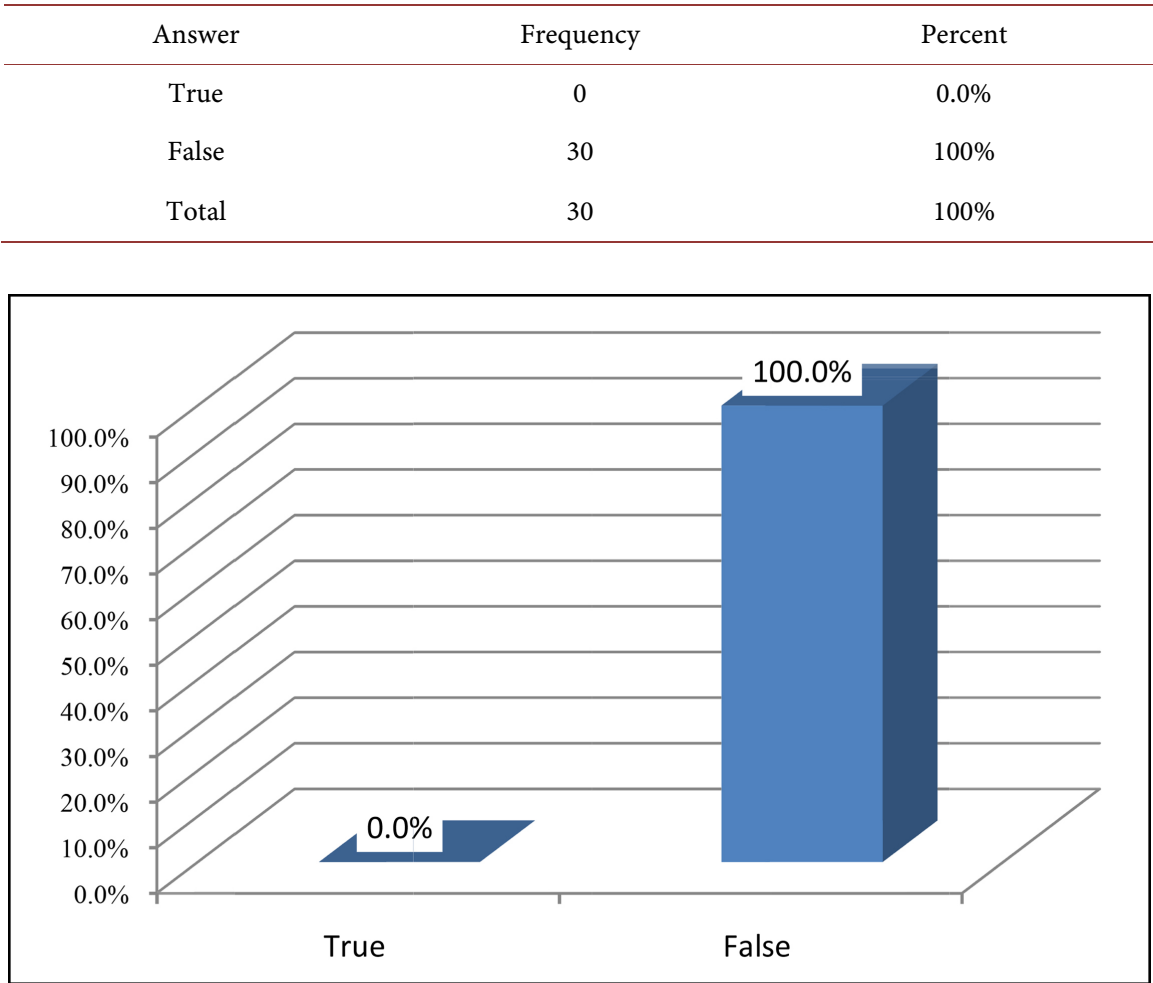

Figure 7. The frequency distribution's analysis for item seven.

Table 8. The frequency distribution's analysis for item eight.

\begin{tabular}{ccc}
\hline Answer & Frequency & Percent \\
\hline True & 18 & $60 \%$ \\
False & 12 & $40 \%$ \\
Total & 30 & $100 \%$ \\
\hline
\end{tabular}

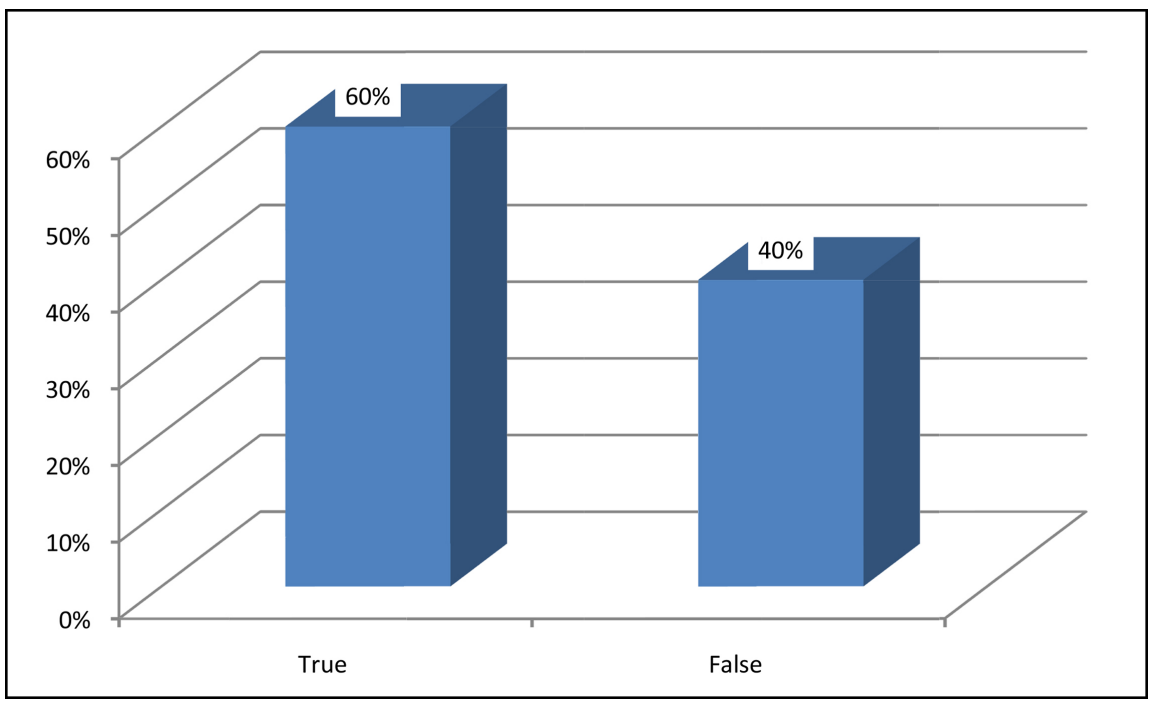

Figure 8. The frequency distribution's analysis for item eight. 
Table 9. The frequency distribution's analysis for item nine.

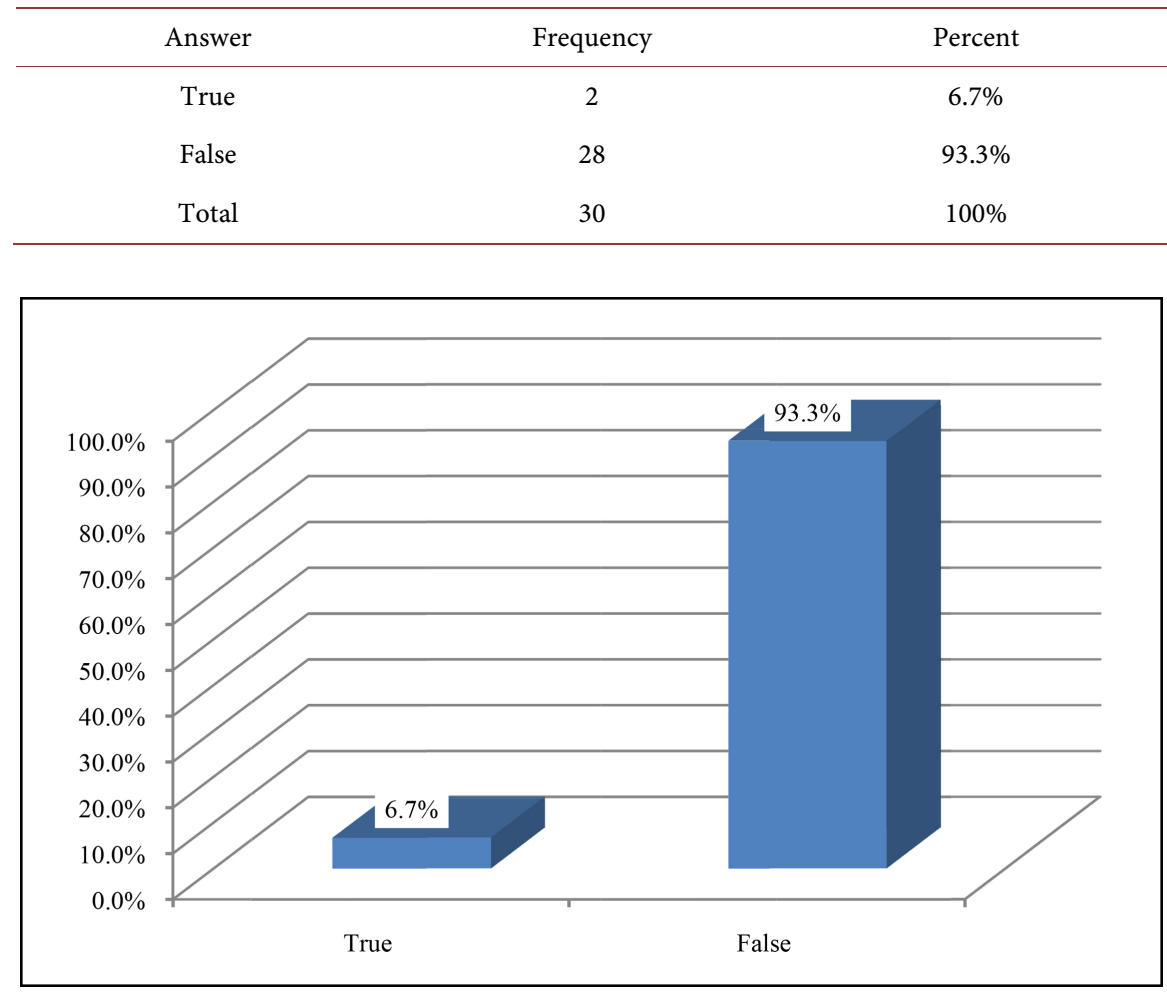

Figure 9. The frequency distribution's analysis for item nine.

Table 10. The frequency distribution's analysis for item ten.

\begin{tabular}{ccc}
\hline Answer & Frequency & Percent \\
\hline True & 11 & $36.7 \%$ \\
False & 19 & $63.3 \%$ \\
Total & 30 & $100 \%$ \\
\hline
\end{tabular}

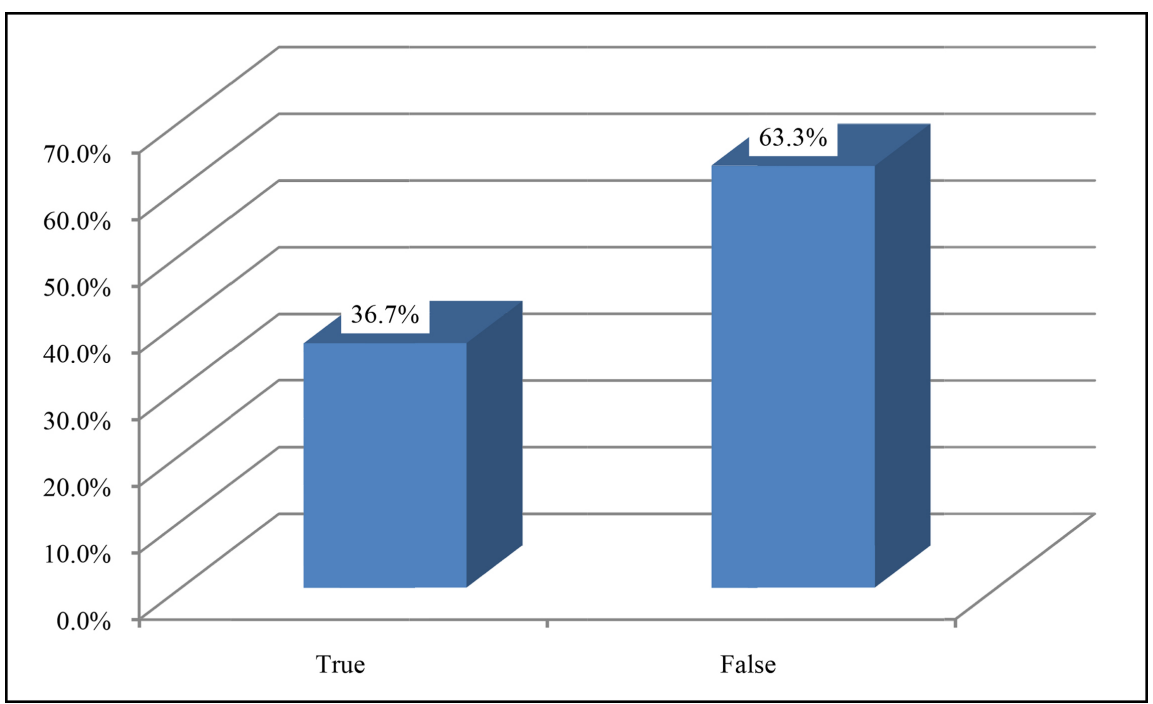

Figure 10. The frequency distribution's analysis for item ten. 
Table 11. The frequency distribution's analysis for item eleven.

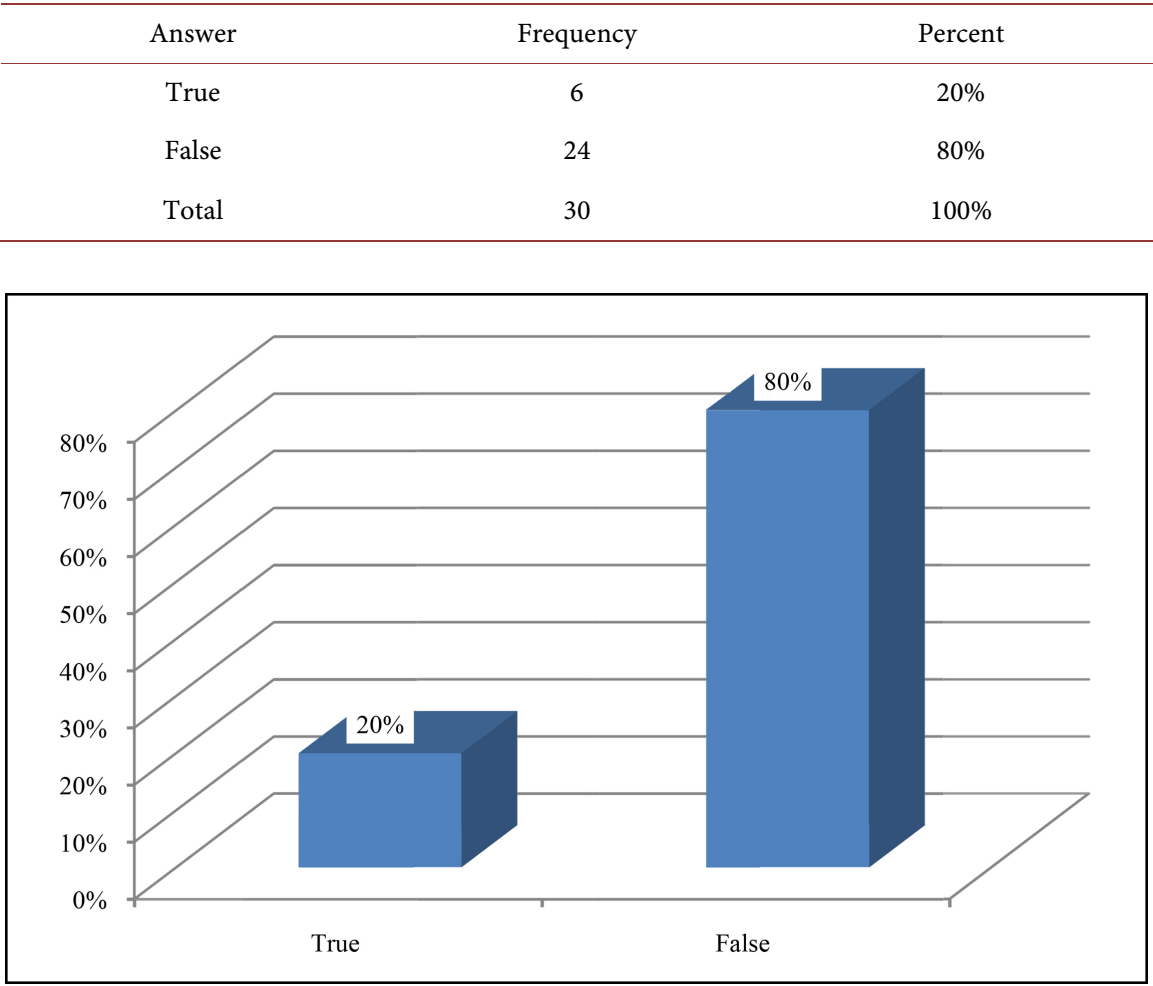

Figure 11. The frequency distribution's analysis for item eleven.

Table 12. The frequency distribution's analysis for item twelve.

\begin{tabular}{ccc}
\hline Answer & Frequency & Percent \\
\hline True & 0 & $0.0 \%$ \\
False & 30 & $100 \%$ \\
Total & 30 & $100 \%$ \\
\hline
\end{tabular}

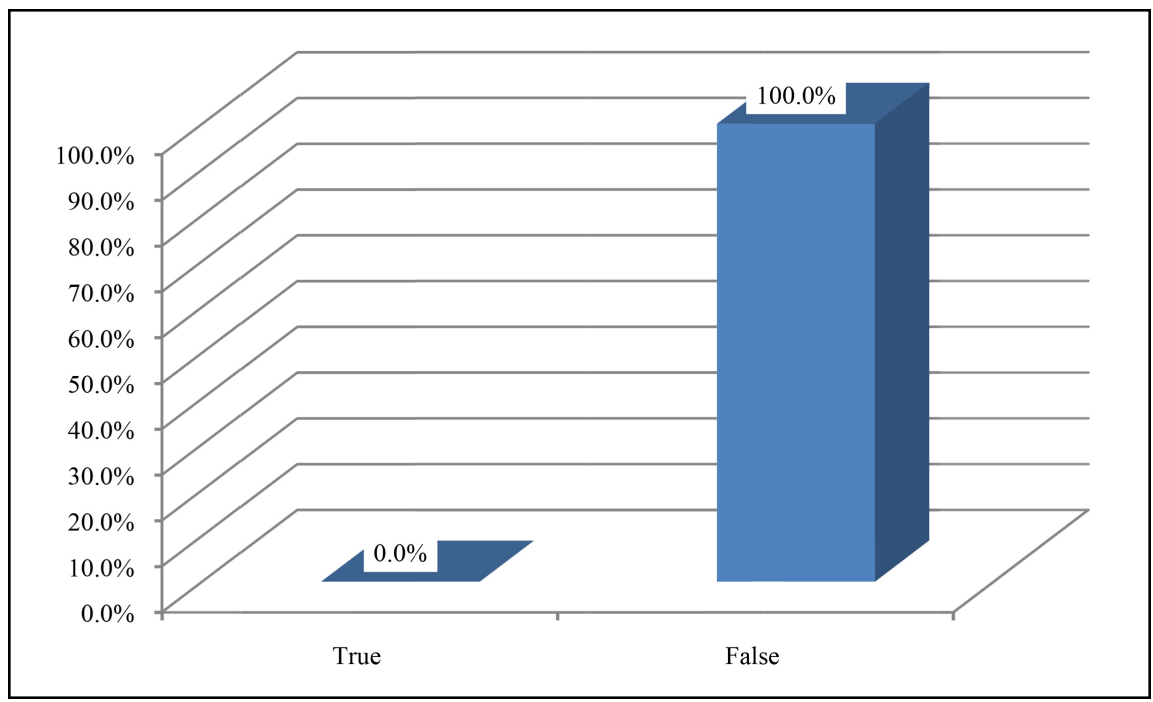

Figure 12. The frequency distribution's analysis for item twelve. 
Table 13. The frequency distribution's analysis for item thirteen.

\begin{tabular}{ccc}
\hline Answer & Frequency & Percent \\
\hline True & 0 & $0.0 \%$ \\
False & 30 & $100 \%$ \\
Total & 30 & $100 \%$ \\
\hline
\end{tabular}

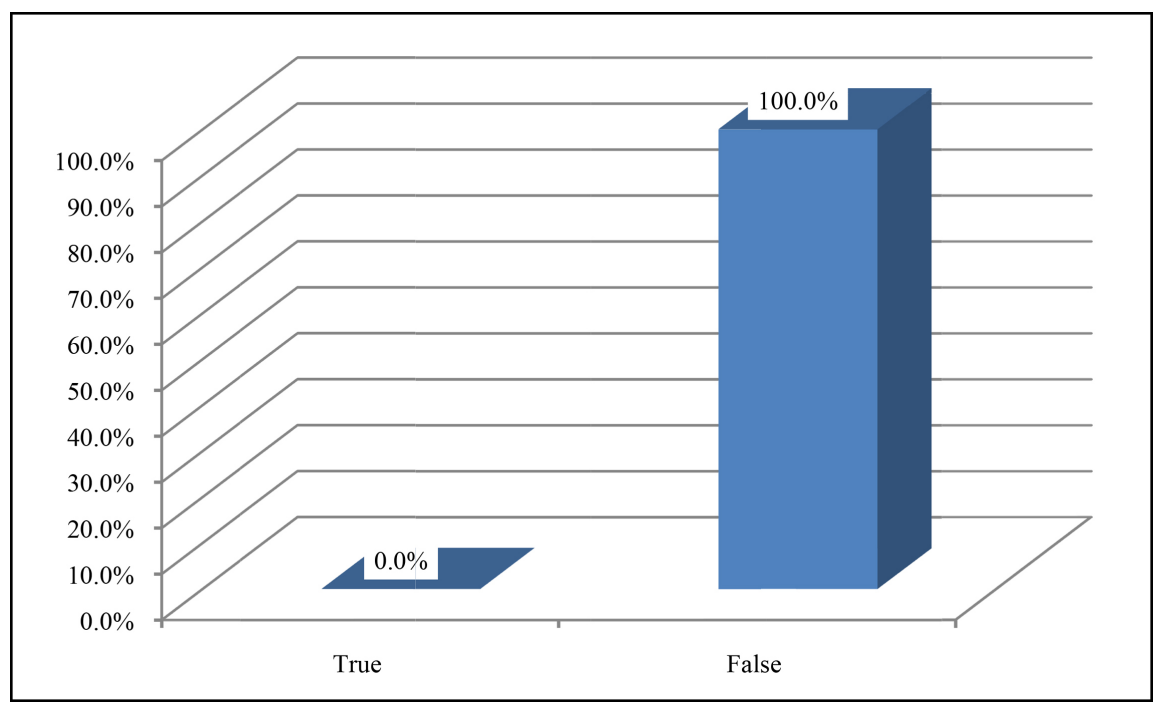

Figure 13. The frequency distribution's analysis for item thirteen.

Table 14. The frequency distribution's analysis for item fourteen.

\begin{tabular}{ccc}
\hline Answer & Frequency & Percent \\
\hline True & 0 & $0.0 \%$ \\
False & 30 & $100 \%$ \\
Total & 30 & $100 \%$ \\
\hline
\end{tabular}

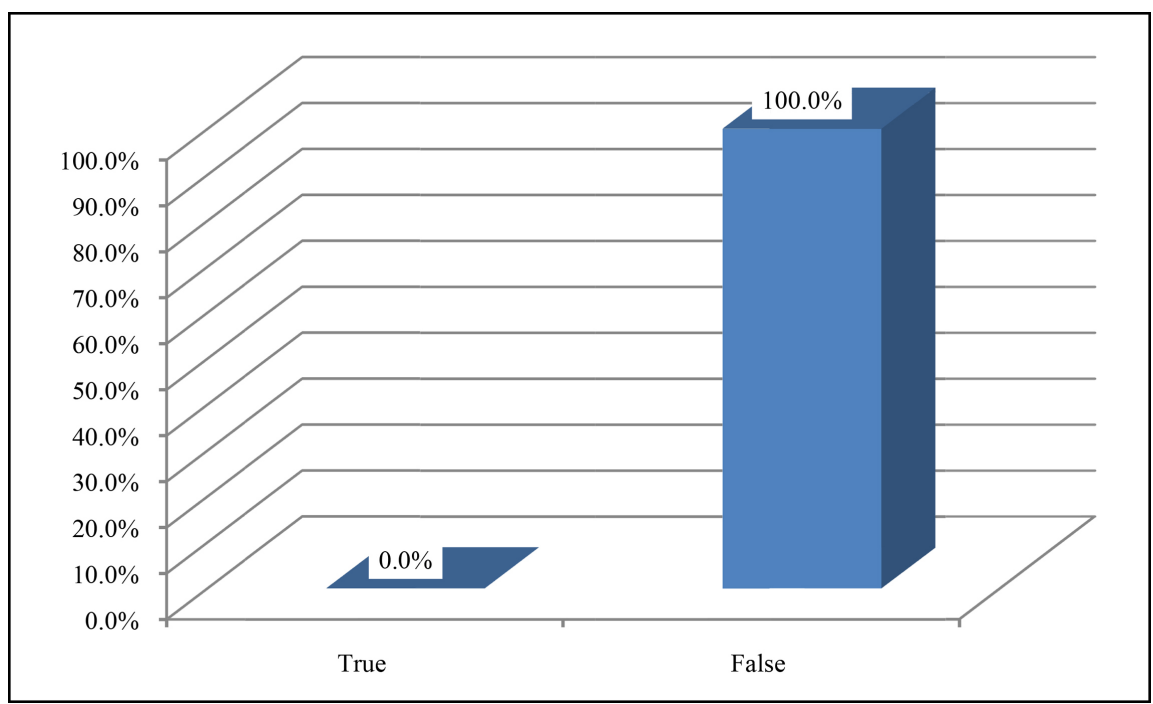

Figure 14. The frequency distribution's analysis for item fourteen. 
Table 15. The frequency distribution's analysis for item fifteen.

\begin{tabular}{ccc}
\hline Answer & Frequency & Percent \\
\hline True & 0 & $0.0 \%$ \\
False & 30 & $100 \%$ \\
Total & 30 & $100 \%$ \\
\hline
\end{tabular}

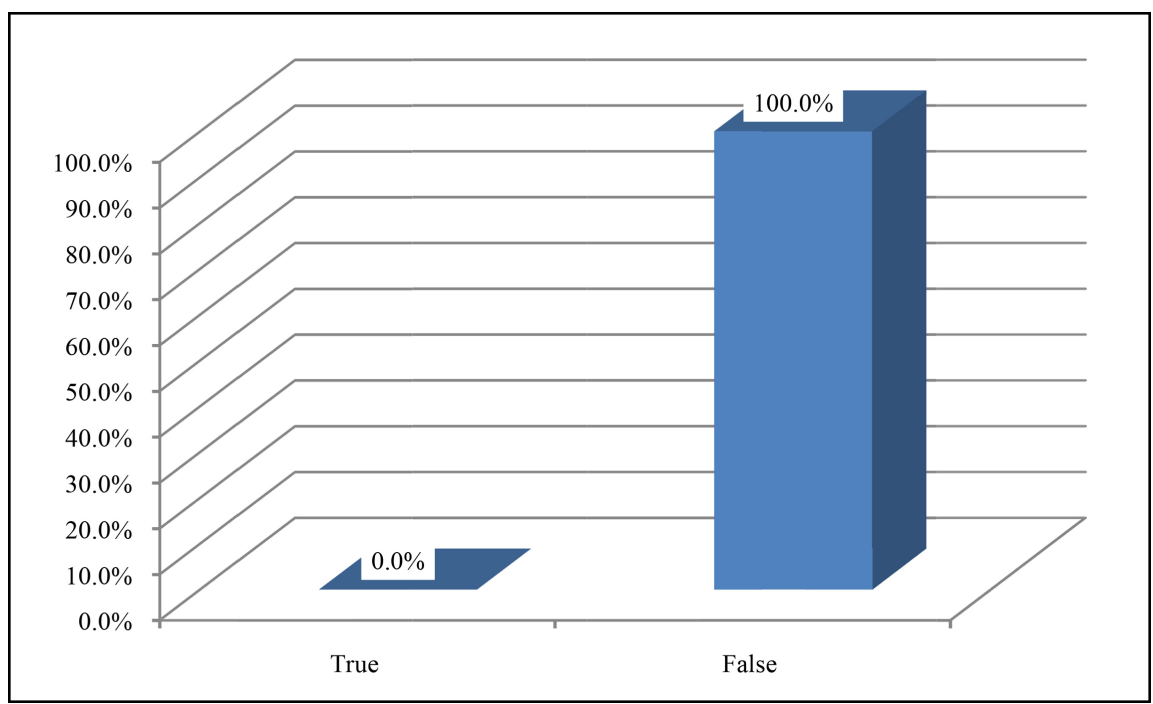

Figure 15. the frequency distribution's analysis for item fifteen.

\section{Conclusion and Implications}

After making careful and deep analysis to the data, the researcher concluded that university students are not aware that using tenses correctly is one of the reasons that prevent the learners to translate correctly. Based on the results presented, they are major conclusions; students have general background about translation. They have very weak background knowledge about how to translate from English into Arabic. They do not have sufficient ability to translate Arabic sentences into English. They are very weak in translating English proverbs into Arabic. They are not acquiring English culture, which negatively affects their abilities of translating English proverbs into Arabic. With the reference to the finding of the study, the researcher recommends

1) The translation should be paid attention when it is taught.

2) It should be taught from the first year.

3) Students should be given many topics to translate during their academic year.

4) They should be taught as much as possible English proverbs during their academic year.

5) The teachers should use motivating methods to enhance the students' level in translation.

Based on the findings of this study, the researcher has made the following suggestions: 
1) Investigating the difficulties of translation and investigating the difficulties of translating English proverbs into Arabic.

2) Investigating the difficulties of translating English proverbs into Arabic.

\section{Acknowledgements}

Thanks to the students who, created all the possibilities for this work. And of course, thanks to my colleagues and friends who, helped me a lot, this paper would not exist without their unceasing commitment. I also dedicate it to my beloved kids.

\section{Conflicts of Interest}

The author declares no conflicts of interest regarding the publication of this paper.

\section{References}

Baker, M. (1992). In Other Words: A Course Book on Translation. London and New York: Routledge. https://doi.org/10.4324/9780203327579

Catford, J. C. (1965). A Linguistic Theory of Translation. Oxford: Oxford University Press.

Farghal, M., \& Shunnaq, A. T. (1999). Translation with Reference to English and Arabic: A Practical Guide. Irbid: Dar Al-Hilal for Translation.

Ghazala, H. (2008). Translation as Problems and Solutions, Special Edition (p. 24). Beirut: Dar Elilm lilmalayin.

Meider, W. (2004). Proverbs: A Handbook. London: Greenwood Press.

Meider, W., \& Dundes, A. (1985). The Wisdom of Many: Essays on the Proverb. New York: Garland.

Mollanazar, H. (2001). Principles and Methodology of Translation. Tehran: SAMT.

Nakhallah, A. (2016).

http://www.qou.edu/english/conferences/firstNationalConference/pdfFiles/ahmadMah er.pdf

Newmark, P. (1988a). A Textbook of Translation. Hertfordshire: Prentice Hall.

Newmark, P. (1988b). Approaches to Translation. Hertfordshire: Prentice Hall.

Newmark, P. (1991). About Translation: Multilingual Matters.

Nida, E. A. (1954). Customs and Cultures. New York: Harper and Bros.

Nida, E. A. (1964). Toward a Science of Translation with Special References to Principles and Procedures Involved in Bible Translating.

Norman, C. (1995). Practice English Grammar Basic. Oxford: Oxford University Press.

Norrick, N. R. (1985a). How Proverbs Mean? Semantic Studies in English Proverbs. Amsterdam: Mouton. https://doi.org/10.1515/9783110881974

Norrick, N. R. (1985b). Semantic Studies in English Proverbs. Berlin: Mouton. https://doi.org/10.1515/9783110881974

Russo, J. (1983). The Poetics of the Ancient Greek Proverb. Journal of Folklore Research, 20, 121-130.

Tailor, A. (2005). Understanding Different Types of Translation. Tubingen: Gunter Narr. 